\title{
A dog bite to the adult scrotum
}

\author{
Dr. D. Saleh, MD; ${ }^{*}$ Dr. David Shaw, MD; Dr. Chandra Shekhar Biyani, MD*
}

\begin{abstract}
Dog bites are a common presentation to emergency departments worldwide. However, presenting symptoms may fail to reveal the severity of an injury. We present such a case.
\end{abstract}

Can Urol Assoc J 2009;3(5):E64-E66

\section{Introduction}

It is estimated that 740 people per 100000 are bitten by dogs every year. ${ }^{1}$ Of these, $50 \%$ are children ${ }^{2}$ and an average of 2.6 per 100000 require hospital admission. Injuries to the external genitalia, in particular to the scrotum, following dog bites are rare when compared to the total number of dog bites. ${ }^{3}$ Most cases reported in the literature are pediatric cases, perhaps due to the relative immobility of the infant or to a dog jealous of the attention given to other family members. ${ }^{2}$ Furthermore, there are no reported cases of unilateral testicular loss in an adult following such an injury. We present a case of a scrotal dog bite in an adult with unique clinical presentation and radiologic and intraoperative findings.

\section{Case report}

A 52-year-old professional visited a client at his home and was bitten to the left side of the scrotum by the client's dog. The patient did not go to the hospital that day because there seemed to be only a lacerated wound, with little damage or pain or other symptoms following the incident. Three days later, the patient developed a tender left scrotum and subsequently went to the hospital emergency room.

On examination, the patient was afebrile and hemodynamically stable. The abdomen was soft. The left hemiscrotum was swollen, erythematous and very tender. There was a single wound approximately $0.5 \mathrm{~cm}$ wide, on the antero-lateral aspect of the left testicle. Exquisite tenderness limited palpation. It was difficult to identify the testis and epididymis separately from a large, tense non-transilluminable mass. The wound was thoroughly irrigated, and antibiotics (oral co-amoxiclav) and tetanus prophylaxis were administered. A scrotal ultrasound scan showed the right testis and epididymis were normal. The left hemiscrotum was swollen and no normal testicular tissue was identified. Within the tunica albuginea, there was an area of hypoechoeic fluid consistent with a hematoma (Fig. 1, Fig. 2). The solid component within, however, was presumed to be testis and some clotted hematoma. Lack of blood flow to the left testis was observed. Doppler signal was absent, implying that the testis was no longer viable.

A defect was observed on the anterior aspect of the tunica albuginea, with testicular content and hematoma extruding out of the tunica into the scrotal sac. Scrotal exploration showed the testicular tissue had entirely extruded from the tunica albuginea and was necrotic (Fig. 3). The epididymis looked normal. The hematoma was evacuated and a scrotal orchidectomy was performed. An ellipse of scrotal skin around the puncture wound was excised. A scrotal drain was left in situ for 2 days postoperatively and removed with no complications.

The patient made an uneventful postoperative recovery and was discharged home on postoperative day 4 . Pathologic findings correlated with intra-operative findings; there was extensive testicular hemorrhage also involving the rete testis. The epididymis was oedematous but not necrotic. The tunica was disrupted and torn, with blood filling between adjacent seminiferous tubules. No malignant cells were observed. We hypothesize that blunt trauma resulted in eventual rupture of a necrotic testis and subsequent extrusion of contents.

\section{Discussion}

Dog bites to the adult scrotum are very rare. Scrotal and testicular trauma can be divided into 3 general groups: blunt, penetrating and avulsion injuries. Blunt trauma refers to injuries in which significant force is applied to the scrotum and testes. It accounts for $85 \%$ of cases. ${ }^{4}$ The most common cause is sport-related injury and rarely straddle injury or motor vehicle accidents. An uncommon testicu- 


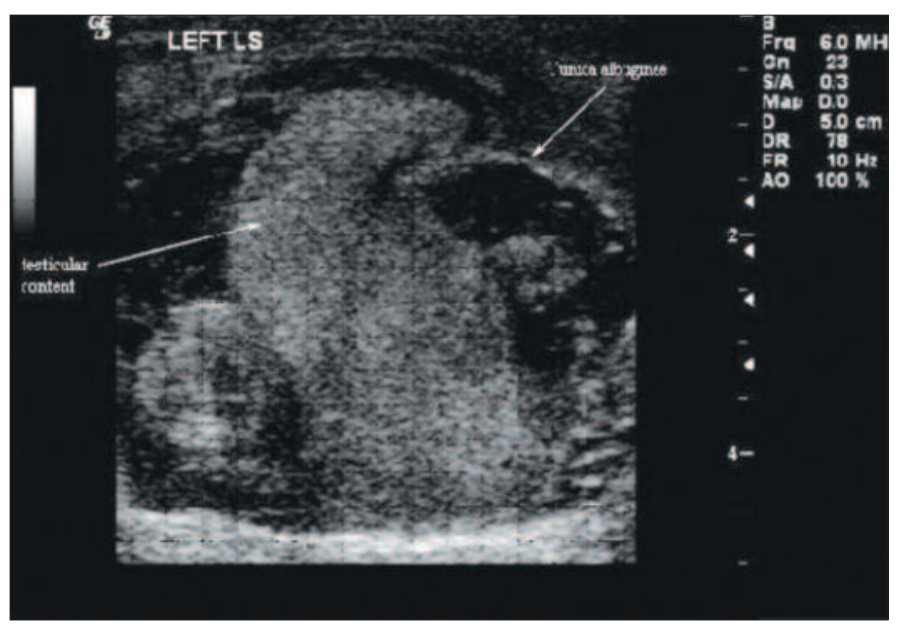

Fig. 1. Acute hematoma within the testicle.

lar injury related to blunt trauma is testicular dislocation. The diagnosis is often delayed, since it is easily overlooked. Most cases are the result of motorcycle accidents and onethird are bilateral.

Penetrating trauma accounts for approximately $15 \%$ of testicular trauma. ${ }^{4}$ The most common causes are gunshot and stab wounds. Other causes include self-mutilation and animal bites (especially dog bites). A dog bite to the scrotum is a relatively uncommon clinical problem. It is usually described in children or patients with mobility difficulties. Most often, scrotal dog bites result in penetrating trauma to the testis. Avulsion injuries of the male scrotum are a rare urological emergency. The most common causes appear to be work accidents (machine pulleys, chains and rotary discs, and agriculture) and casual traumas. ${ }^{3}$

This case is unique in that the clinical history and condition of scrotal tissue indicated only a minor penetrating injury, yet radiologic and intra-operative findings indicated blunt damage and destruction of the testicle. We postu-

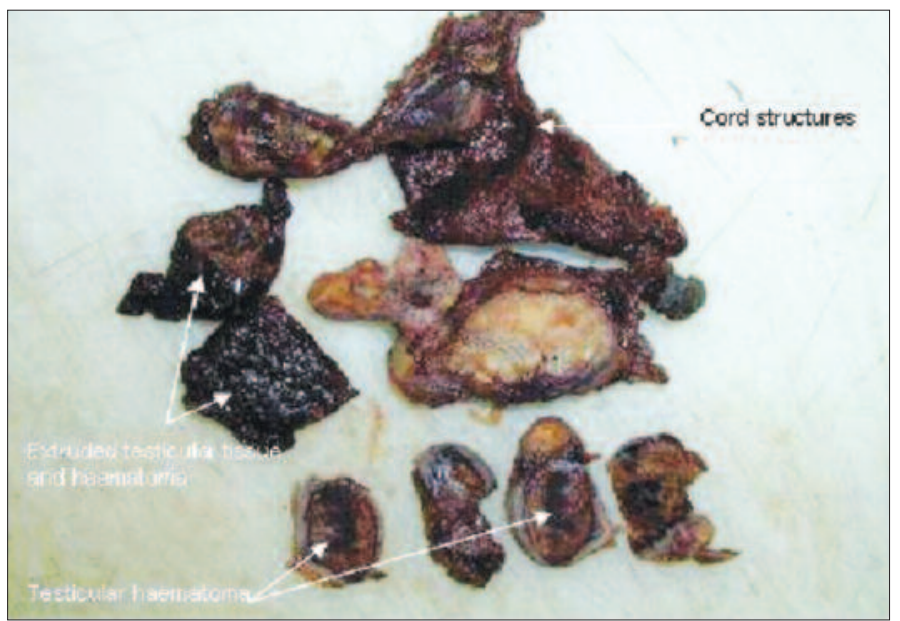

Fig. 3. Macroscopic specimen following dissection by pathology department.

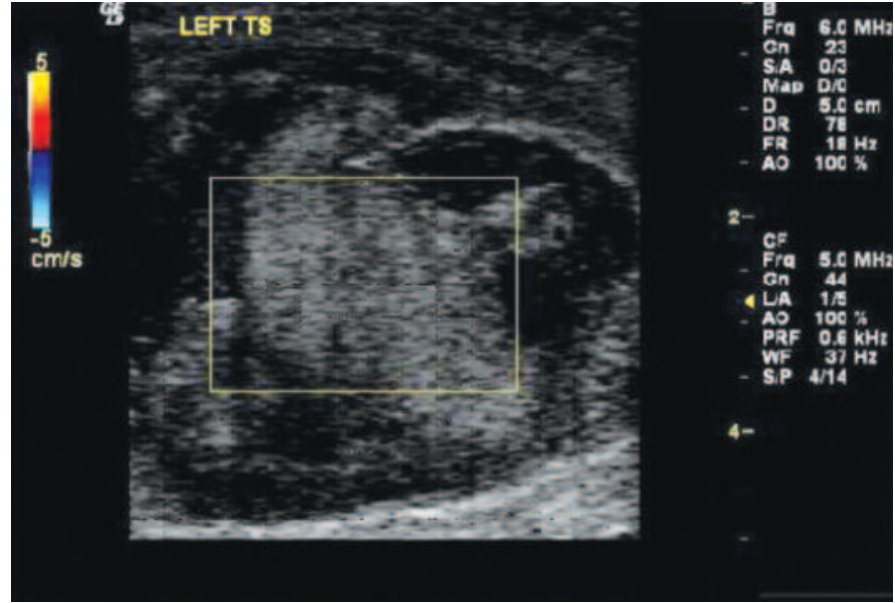

Fig. 2. Hematoma extruded from the testicle with no testicular blood flow.

lated that, as the defect in the tunica albuginea was distant from the cutaneous entry point of the bite, the testicular rupture was related to significant pressure exerted from the flatter anterior canine teeth. The biting force of canine jaws can vary from 44.96 pounds per square inch (PSI) to 4610.74 PSI (310 kPa to $31790 \mathrm{kPa}$ ) depending on the breed of dog and the training received. The tunica albuginea is a layer of fibrous connective tissue surrounding the testis; approximately $110 \mathrm{lbs}(50 \mathrm{~kg})$ of force is required to fracture tunica albuginea. ${ }^{5,6} \mathrm{~A}$ dog bite, therefore, has the potential for exerting enough force to fracture the tunica albuginea.

A smaller report documented adult scrotal bites in four men in an 8-year period, none of whom had testicular, epididymal or cord trauma. ${ }^{7}$ Interestingly, a recent case series of 65 patients assessed the use of ultrasound in blunt testicular injuries and found that 32 patients had radiological rupture. ${ }^{8}$ On exploration, 30 of them had a ruptured tunica albuginea and only 5 of those required orchidectomy, 4 of whom had a delayed presentation of over 48 hours. $^{8}$ There are relatively more reports of paediatric scrotal bites by dogs, and most likely these bites are not eating bites; they are the result of an attack. However, only 1 case in the literature reported any testicular damage. ${ }^{9,10}$

This case illustrates that the immediately visible puncture of a dog bite may not reflect more serious underlying blunt trauma. A scrotal ultrasound is a useful diagnostic tool in such cases.

*Department of Urology, Pinderfields General Hospital, Aberford Road, Wakefield, UK; †Department of Radiology, Pinderfields General Hospital, Aberford Road, Wakefield, UK

This paper has been peer-reviewed.

Competing interests: None declared. 
Saleh et al.

\section{References}

1. Wolff K. Management of animal bite injuries of the face: experience in 94 patients. J Oral Maxillofac Surg 1998:56:838-43.

2. Morgan M. Palmer J. Dog Bites. BMJ 2007;334:413-7.

3. Van der Horst C, Martinez-Portillo FJ, Seif C, et al. Male genital injuries: Diagnosis and treatment. BJU Int 2004;93:927-30.

4. Santucci RA, Battino BS, Terlecki RP. Testicular trauma. http://www.emedicine.com/med/topic2859.htm. Accessed November 27, 2008.

5. Presutti RJ. Prevention and treatment of dog bites Am J Phys 2001;63:1567-72.

6. Rosenthal DU. When K-9s cause chaos: an examination of police dog policies and their liabilities. New York Law School of Human Rights 1994;11:279-310.
7. Cummings JM, Boullier JA. Scrotal dog bites. J Urol 2000;164:57-8.

8. Buckley JC, McAninch JW. Use of ultrasonography for the diagnosis of testicular injuries in blunt scrotal trauma. J Urol 2006;175:175-8.

9. Budhiraja S, Ghei M. Scrotal dog bite in an infant Pedaitr Surg Int 2002;18:206-7.

10. Ku JH, Kim HH. Renal failure in a patient with amputated penis by dog bite. Nephrol Dial Transplant 2005;20:1485-6.

Correspondence: Dr. Chandra Shekhar Biyani, Department of Urology, Pinderfields General Hospital, Aberford Road, Wakefield, WF1 4DG, UK; fax +44 1924 212027; shekharbiyani@hotmail.com 